\section{AN INSULIN-RESISTANT DIABETIC}

BY

\author{
R. D. CLAY, M.B., B.S. \\ AND
}

R. D. LAWRENCE, M.D., F.R.C.P.

(From the Diabetic Department, King's College Hospital)

We are recording an extreme case of insulin resistance in a diabetic who showed no response to hundreds of units a day. None of the complicating factors which are recognized as interfering with insulin action were present. Such factors have been classified by MacBryde ${ }^{1}$ and others as follows: (1) infections ; (2) other endocrine disease-hyperthyroidism, pituitary disorders (?), suprarenal disorders ; (3) hepatic disorders, including haemochromatosis ; (4) pancreatic destructions; (5) cardiac decompensation and extreme circulatory failure. When any of these conditions complicates diabetes it is well recognized that abnormally large doses of insulin are needed to abolish ketosis and control blood sugar.

In the case to be recorded heart disease was present, but it is not considered that this alone should account for the inefficacy of the very large amounts of insulin which were given. Root, in 1929, calculated that a " completely diabetic " subject would require about 200 units of insulin daily. In a few cases more than this is required, but usually one of the factors mentioned above is present, and even then really large doses of insulin produce the usual effect.

There is, however, an extremely small group of insulinresistant cases in which no explanatory cause can be found, and the present case seems to belong to that group. In our previous experience (R. D. L.), however, all cases have responded to insulin when the dose was progressively raised, whereas the present one showed no response.

\section{Case Record}

The patient, a slightly obese man aged 63 , was in good health until April, 1931, when he developed a coronary thrombosis and came under the care of Dr. IV. Maxwell Penny, to whom we are indebted for his history. From this attack the patient made a fairly good recovery. In October, 1932, he became dyspnoeic, and soft systolic cardiac murmurs were present. At this time both (?) pernicious anaemia and diabetes were diagnosed (red blood cells, $2,160,000$ per c.mm. haemoglobin, 35 per cent.). The blood count rose to 4.6 million with hepatex, and the diabetes required 60 to 90 units a day for its control for some weeks only, while ascites and pleural effusions were present. Later the glycosuria was con trolled by diet alone.

Apart from a return of dyspnoea early in 1934, which responded to treatment, the patient remained fairly well until October 19th, 1934, when severe glycosuria and ketonuria were found to have recurred after a "cold " and remainel uncontrolled by diet. A week later insulin was again started, and was increased to $\mathbf{4 0}$ units three times daily without improvement of the diabetic condition.

On November 6th the patient was admitted to King's College Hospital. The temperature was subnormal, the pulse feeble (110 per minute), and the blood pressure $105 / 75$. The heart was enlarged, but the apex beat could not be defined as marked pulmonary emphysema was present. Evidence of cardiac failure-such as basal or generalized oedema, enlarged liver, or venous congestion-was entirely absent. The kneeand ankle-jerks were absent, but no other neurological abnormalities were found.

The urine contained 8.2 per cent. of sugar, large amounts of ketone bodies (strongly positive $\mathrm{FeCl}_{3}$ test), and a trace of albumin. The blood sugar on admission-six hours after 100 units of insulin-was $\mathbf{0 . 3 5 4}$ per cent., but clin:cal signs of impending coma were absent and remained absent throughout the illness. Carbohydrate ( 30 grams) and insulin (50 units)

\footnotetext{
${ }^{1}$ MacBryde: Arch. Int. Med., 1933, lii, 952.
}

were given four-hourly without any reduction of the ketonuria and glycosuria, neither of which showed any improvement until the patient's death six days later; nor was there any significant change in the blood sugar. The carbohydrate was finally increased to 60 grams four-hourly and insulin to 160 units four-hourly as shown in the table. Some of the insulin was given intravenously, and there was no reason to think that the subcutaneous injections were not absorbed.

\begin{tabular}{|c|c|c|c|c|c|c|}
\hline 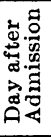 & 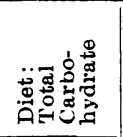 & 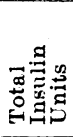 & 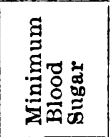 & 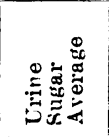 & 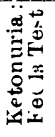 & $\begin{array}{c}\text { Blood Pressure and } \\
\text { Pulse }\end{array}$ \\
\hline 1 & 120 grams & 190 & $\begin{array}{c}\text { Per cent } \\
0.354\end{array}$ & $\begin{array}{c}\text { Per cent. } \\
8\end{array}$ & $+t$ & 105/75; pulse, 110 \\
\hline 2 & $150 \quad$, & 220 & 0.291 & 7 & ++ & 12470 ; pulse, 80 \\
\hline 3 & $180 \quad$, & 560 & 0.310 & 8 & ++ & 103/75; pulse, 9) \\
\hline 4 & $\begin{array}{l}\text { Glucose } \\
300 \text { grams }\end{array}$ & 720 & $0.37 J$ & 10 & ++ & $112-158 / 2 C-95$ \\
\hline 5 & $\begin{array}{l}\text { Laevulose } \\
360 \text { grams }\end{array}$ & 960 & 0.403 & 12 & ++ & 130/90: pulse, 135 \\
\hline
\end{tabular}

The cardiac condition improved temporarily under the influence of digitalis and alcohol, the blood pressure rising at its highest to $150 / 92$ and varying considerably (see table). Shortly before death marked pulsus alternans was present, and the pulse rate rose to 136 . The patient never became comatose, air-hunger and vomiting were absent, and he was never obviously dehydrated, though a blood count a few hours before death revealed: red blood cells, $6,22 \theta, 000$ per c.mm. ; haemoglobin, 118 per cent. ; and a leucocytosis of 14,400 per c.mm. with $\mathbf{8 4 . 8}$ polymorphs, though no infection was present, suggesting dehydration.

A sample of "blood taken three days before death showed the following: alkali reserve, 45 vols. per cent. ; blood urea, $49 \mathrm{mg}$. per $100 \mathrm{c} . \mathrm{cm}$. ; blood uric acid, $3.5 \mathrm{mg}$. per $100 \mathrm{c.cm}$. ; serum protein, 6.1 per cent. ; chlorides (plasma), $500 \mathrm{mg}$. per cent.

The urine always contained varying amounts of sugarbetween 5 and 12 per cent. The albuminuria increased as the iilness proceeded, but was never heavy. The volume of urine remained high (average, 2,000 to $3,000 \mathrm{c} . \mathrm{cm}$.) until death. No casts and no other chemical abnormalities were present, and the chloride content was only slightly reduced.

\section{Post-mortem Findings}

(Abridged from Report by Dr. A. Gilpin)

Lungs._-Slight bronchitis and non-inflammatory oedema; no pneumonia.

Heart and Blood Vessels.-Moderate generalized atheroma and old thrombosis of anterior descending branch of left coronary artery, with thin heart muscle in infarcted area; right auricle dilated ; compensatory hypertrophy of left auricle and ventricle. Muscle fibres in healthier part of ventricle showed brown atrophy and poor striation.

Liver.-Normal weight, terminal congestion; slight fatty degeneration, mostly portal. Gall-bladder, not infected, contained four soft stones.

Kidneys.-Pale, congested, senile atrophy: glomeruli all normal microscopically.

Bone Marrow.-Showed predominantly normoblastic activity ; a few megaloblasts seen.

Endocrine Glands.-Entirely normal macroscopically and microscopically. Islets of Langerhans seemed normally abundant, and showed no inflammation or degeneration. Pituitary showed normal proportion of basophil and eosinophil cells.

\section{Discussion}

There was no evidence of any insulin action as judged by the unchanging hyperglycaemia, glycosuria, and, more important still, ketosis. The ketosis showed that abundantly available glucose was not being oxidized by enormous doses of insulin, which is unique in our experience, even in almost moribund diabetics. In view of the urgency of the case it was hardly permissible to study the effect of insulin alone without covering carbohydrate, and a fall in blood sugar would almost certainly have 
occurred with such a heavy excretion of sugar per se, whether the insulin acted or not. The essential criterion, the unvarying ketosis, showed that no appreciable insulin action took place.

The clinical condition and the post-mortem findings indicated no important abnormality, except the cardiac condition. To this, therefore, the failure in insulin action might be ascribed. But the pulse pressure, the absence of oedema, hepatomegaly, and venous congestion, and the high volume of urine showed that a reasonably adequate circulation was being maintained until just before death. We feel, therefore, that the heart condition does not explain the failure of insulin action, and the case seems worth recording.

\section{Summary}

A case of diabetes is recorded which failed to respond to hundreds of units of insulin a day.

\section{SOME EFFECTS OF ARTIFICIAL HEAT ON THE CIRCULATION IN COLD TEMPERATE CLIMATES *}

\author{
BY \\ R. FORTESCUE FOX, M.D., F.R.C.P.
}

From observations on the effects of cold and heat in chronic rheumatism it seems clear that in a warm-blooded animal a small permanent deficiency of heat may be a factor in the production of disease. The delicate mechanisms of heat production and loss which protect the body against a deficiency of heat may break down. The production of heat cannot always keep pace with its loss, and exposure to cold is followed by a fall in body temperature, first on the surface and afterwards in deeper parts. The thermostable animal has become thermolabile. At the other end of the scale it seems equally clear that upon exposure to extreme heat in the Tropics, and in some fevers, heat loss cannot keep pace with heat production, and that there is an accumulation of heat in the body which may lead to fatal results.

Here are two categories of disease arising from uncompensated exposure to cold or heat. They show a break in thermo-regulation in one direction or in the other. Micro-organisms may also be concerned in these diseases, but chilling or overheating plays an essential part in their causation. The climate of the northern temperate region has for its chief characteristic an incessant conflict of polar and Atlantic currents, and consequent abrupt changes in temperature. This is, therefore, the region in which the effects of sudden changes of temperature should be looked for in sensitive subjects, and especialiy the effects of repeated and chronic chill.

One lesson which may be learned from the study of rheumatism is that the effects of cold are shown very quickly, and perhaps first of all, in the circulation. Subnormal temperatures are common in rheumatic limbs. It seems that the capillary bed is greatly reduced, and that an abnormal number of capillaries in the cutaneous network are closed. It is known that rheumatism is frequent in exposed parts ; rheumatic joints are very near the surface of the body, and the articular cartilages (loci minoris resistentiae) are ill supplied with blood. This has led to the hypothesis that a large and prevalent type of rheumatic disease is connected with deficiency of blood supply, the result of external cold. Certainly the beneficial effects of protection against chill and the removal

* Read before the South Essex Division of the British Medical Association, February 12th, 1935. of pain, stiffness, and swelling by heat give support to this hypothesis.

The gradual effects of cold on the circulation in the skin and extremities need no description, nor yet the immediate effect of, say, \& brief hot bath (three minutes at $100^{\circ}$ to $105^{\circ}$ ). The skin, which was the coldest organ of the body, becomes the hottest; it changes in colour from a dull white to bright red. The pulse is accelerated, soft, and large, the muscles relaxed, and perspiration breaks out. The observation of this sequence of events is particularly instructive in men who have been subjected to hard labour and exposure. Chill, fatigue, pain, and stiffness give place to a sense of warmth, comfort, and vigour.

\section{Degree and Duration of Heat}

The cardinal twofold reaction to heat, not unlike the reaction to many drugs, is shown in the restorative effect of brief baths and the injurious after-effects (the " thermal debility ") of prolonged heat. The medical importance of these physiological facts and their bearing on the treatment of many chronic disorders are insufficiently realized. But even rough-and-ready rules are of some service. Baths over blood heat, prolonged for more than ten minutes, are always injurious in health. In cases of low blood pressure or myocardial weakness only a few seconds' immersion in a bath at blood heat can be allowed. There are great individual differences in the twofold reaction both to heat and to cold. Fairly robust persons may, by training, greatly increase their power of accommodation. Even when it has been considerably diminished, as in chronic disease, it may often be re-educated by judicious thermal applications.

Those who have prescribed medical baths for many years must realize the governing importance of the dosage of heat. Sometimes it must be very precisely measured. In effervescent baths for circulatory cases a single degree may make the difference between a stimulant or a sedative effect. In addition to temperature, there is always the " fine adjustment of duration." Where the patient is progressing well a minute may often be added every two or three days. In each case the duration of the bath must be regulated by the circulatory reaction which it evokes. The disregard of dosage in hot baths in the last century caused a strong aversion to their use, and as a result baths of all kinds were forbidden in heart cases. Similar mistakes were made with baths of low temperatures. Even iced baths were given in typhoid fever, in ignorance of the fact that in febrile diseases external cold below $65^{\circ}$ is a dangerous depressant. Such a use of powerful agents, which are really invaluable stimulants or sedatives, did much to bring hydrotherapy into disrepute. [But if no guidance had been given in the use of morphine and strychnine they would certainly have also been banned.]

To their credit practitioners at spas have carefully studied the administration of baths. Good effects often follow their precise use in circulatory disorders-for example, in high blood pressure and hyperpieşia, as described in Dr. Edgecombe's paper presented at the annual meeting of the British Medical Association at Eastbourne. ${ }^{1}$

\section{Consensual Reaction to Heat}

Popular medicine everywhere relies a great deal on the local use of heat carried by hot bottles, bricks, flatirons, poultices, fomentations, steam, warming-pans, footbaths, et hoc genus omne. Everyone knows that hyperaemia induced by external heat is very soothing in a great variety of painful conditions. The rationale of such methods is now better understood In addition to their local effects-relief of pain and circulatory tension, dilatation of capillaries and increased circulation-it is now

${ }^{1}$ British Medical Journal, 1931, ii, 319. 